\title{
Clinico Diagnostic Studies on Reticular Abscess in Cattle - A Review of Four Cases
}

\author{
K. Sasikala ${ }^{1}$, G. Vijayakumar ${ }^{1 *}$, S. Sivaraman ${ }^{1}$ and G.A. Balasubramaniam ${ }^{2}$ \\ ${ }^{1}$ Department of Veterinary Clinical Medicine, ${ }^{2}$ Department of Veterinary Pathology, \\ Veterinary College and Research Institute, Namakkal 637 002, Tamilnadu Veterinary and \\ Animal Sciences University, Chennai, Tamil Nadu, India \\ *Corresponding author
}

\section{A B S T R A C T}

\begin{tabular}{|l|}
\hline K e y w or d s \\
Cattle, Radiography, \\
$\begin{array}{l}\text { Ultrasonography, } \\
\text { Reticular abscess, } \\
\text { Therapy }\end{array}$ \\
\hline Article Info \\
\hline $\begin{array}{l}\text { Accepted: } \\
\text { 07 April } 2018 \\
\text { Available Online: } \\
10 \text { May } 2018\end{array}$ \\
\hline
\end{tabular}

\section{Introduction}

Cattle's indiscriminate eating habits make them susceptible to inadvertent ingestion of foreign bodies with subsequent penetration of a fore stomach compartment. Reticular abscess in bovines is a frequent complication of traumatic reticuloperitonitis/ foreign body syndrome. It causes severe loss of production and production ability and sometimes death of the animal (Radostits et al., 2007). The present paper describes clinico diagnostic studies and its management on reticular abscess in four cattle.
Three Holstein Friesian cross bred and one Jersey cross bred cattles were reported with the history of anorexia, scanty faeces, recurrent tympany and pyrexia for 3-5 days. Clinical examination revealed scanty faeces, recurrent tympany, pyrexia, bruxism, tachypnoea and tachycardia. Haemato-biochemistry revealed neutrophilia with leukocytosis and significantly elevated mean aspartate aminotransferase and globulin values. No change in silhouette of reticulum could be appreciated on radiography. Ultrasonography revealed anechoic cystic structure with echogenic capsule of the reticular wall. Video endoscopy by physical restrain could not appreciate specific changes. Conservative medical treatment was attempted with ceftriaxone antibiotic and fluid therapy. Owners sold the animal as there was no significant clinical improvement after therapy. 
significantly elevated aspartate aminotransferase and globulin values were noticed on haemato-biochemical examination in all the cattle. Rumen fluid examination was normal. No change in silhouette of reticulum could be appreciated on radiography (Fig. 1). On ultrasonography echogenic capsule with anechoic cavity with occasional echogenic internal spots were visualized (Fig. 2). The variation in echogenicity varied based on density and amount of pus cells and inflammatory exudates inside the abscess. High content of pus cells gave more echogenicity and indicated long standing conditions. Reticuloscopy was performed using (Olympus ${ }^{\mathrm{TM}}$ GIF V70; Olympus Corporation, Japan) flexible video endoscope with a diameter of $8 \mathrm{~mm}$ and a usable length of $160 \mathrm{~cm}$ that featured a channel for instruments and navigation system allowing the endoscope to be moved in two directions (upward $180^{\circ}$ and downwards $100^{\circ}$ ). The instrument was equipped with a halogen light source, an irrigation system, an insufflation system and recording devices. The use of image and data archiving system allowed digital recording of the endoscopic findings during examination. Endoscopic procedure of passing the endoscope upto oesophagus as described by Franz and Baumgartner (2002) and up to reticulum as described by Sasikala $e t$ al., (2017) was followed and this procedure could not appreciate specific changes in reticulum with abscess on outer wall (Fig. 3).

\section{Treatment and Discussion}

Conservative medical treatment was attempted as the owners were not willing for surgical option. All the animals with reticular abscess were administered with ceftriaxone (@5 $\mathrm{mg} / \mathrm{kg}$ IV twice daily) and fluid therapy (DNS @ $10 \mathrm{ml} / \mathrm{kg}$ IV twice daily) for 5 days. No significant clinical improvement was appreciated even on $5^{\text {th }}$ day of treatment and owners subsequently sold the animal. Reticular abscesses are caused by penetration of a metallic foreign body through the reticular wall (Abdelaal et al., 2009). Radostits et al., (2007) reported that the most common clinical signs noticed in animals with reticular abscesses were poor body condition, pyrexia, tachycardia, bruxism, mild ruminal tympany and impaired rumen motility. The clinical signs noticed in the present study were in agreement with the above authors. Athar et al., (2010) reported elevated total leukocyte counts, neutrophilia and normal mean haemoglobin and PCV values with elevated globulin values in bovines with reticular abscess. Similar findings were recorded in the present study.

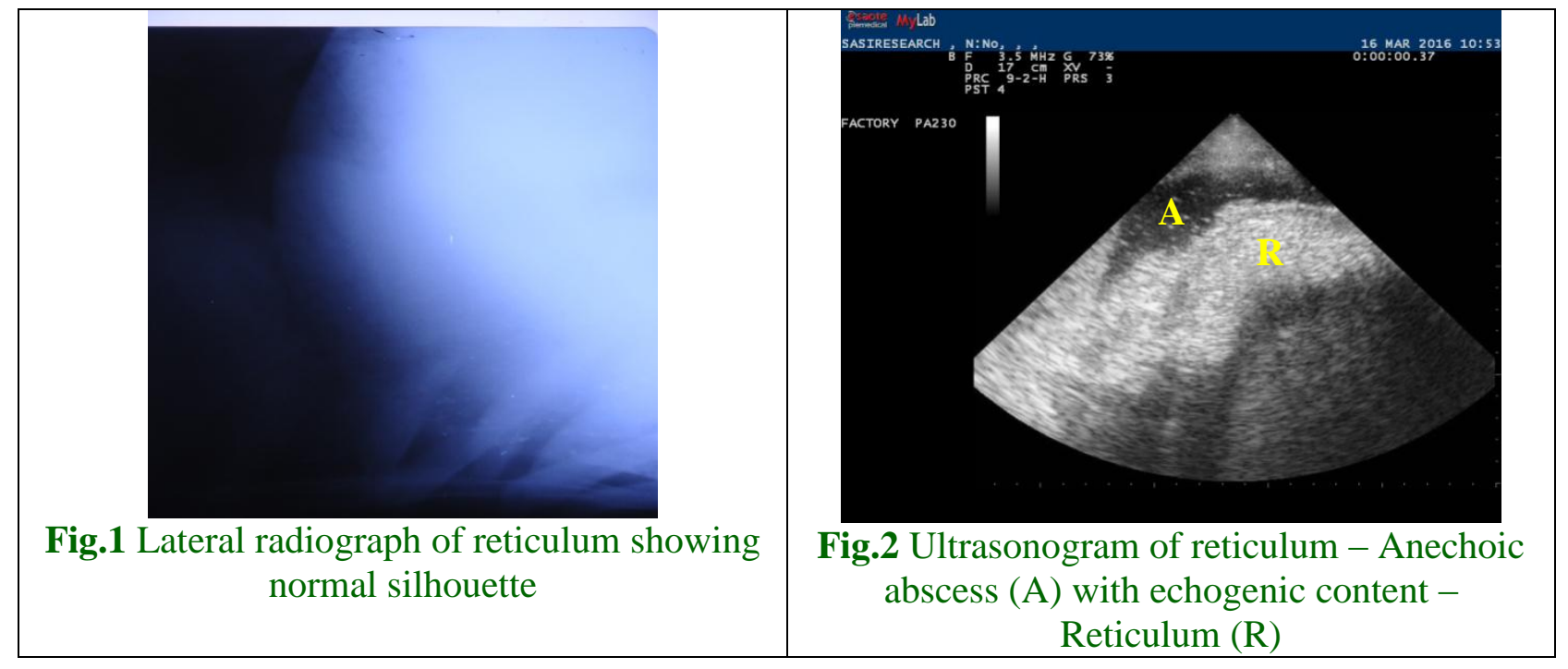




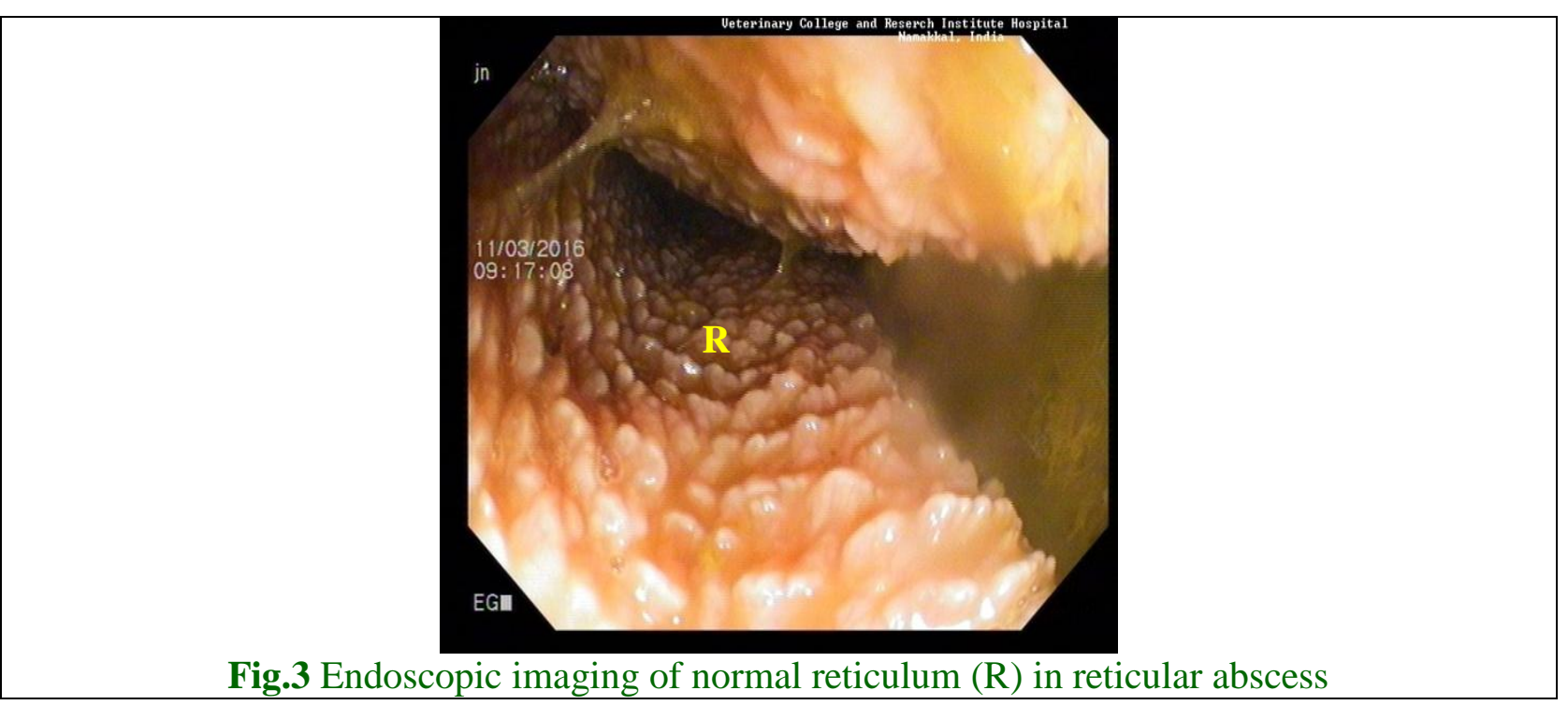

No change in silhouette of reticulum in radiography of the present study could be due to the insufficient density of the foreign bodies to be visualized in the radiograph and owing to the increased thickness of the thorax/ abdomen of the cattle. Non visualization of reticular abscess through radiography was reported by the Saini et al., (2005) and Kumar et al., (2008). Saini et al., (2005) stated that radiography was not considered as a reliable tool for diagnosis of reticular abscess and Kumar et al., (2008) diagnosed reticular abscess only in 5 out of 11 cases subjected for radiographic examination. Braun et al., (1998) and Omidi (2008) observed reticular abscess as echogenic capsule with a hypoechogenic center on ultrasonography. Similar findings were recorded in the present study. Endoscopic imaging is highly useful for the diagnosis of intraluminal changes associated with diseases of reticulum in cattle. Conservative medical treatment for the management of reticular abscess in four cattle using ceftriaxone and fluid therapy as suggested by Athar et al., (2010) was carried out.

Ultrasonography was more reliable than radiography in the diagnosis of cattle with reticular abscess.

\section{Acknowledgement}

The authors are very thankful to the Dean, Veterinary College and Research Institute, Namakkal for the facilities provided during the study.

\section{References}

Abdelaal, A. M., Floeck. M., Maghawry, M. and Baumgartner, W. 2009. Clinical and ultrasonographic differences between cattle and buffaloes with various sequelae of traumatic reticuloperitonitis. Vet. Med., 54: 399-406.

Athar, H., Mohindroo, J., Kumar, A., Singh, K. and Sangwan, V. 2010. Diagnosis and surgical management of reticular abscess in bovines. Indian J. Vet. Surg., 31: 33-36.

Braun, U., Iselin, U., Lischer, C. and Fluri, E. 1998. Ultrasonographic findings in five cows before and after treatment of reticular abscesses. Vet. Rec., 142: 184189.

Franz, S. and Baumgartner, W. 2002. A retrospective study of oesophageal endoscopy in cattle and oesophagoscopy for diagnosis of mucosal disease. Vet. J., 163: 205-210. 
Kumar, A., Sangwan, V., Mohindroo, J., Singh, S. S., Saini, N. S., Chachra, D. and Kaur, G. 2008. Diagnostic and prognostic indicators, antibacterial sensitivity pattern and surgical treatment of perireticular abscess in cows and buffaloes. Indian J. Anim. Sci., 78: 1329-1332.

Omidi, A., 2008. Less common complication of traumatic reticulitis in cattle: Abscess on left thoracic wall. Asian J. Anim. Vet. Adv., 3: 381-385.

Radostits, O.M., Gay, C.C., Hinchcliff, K.W. and Constable, P.D. 2007. Veterinary Medicine. A textbook of the diseases of cattle, horses, sheep, pigs and goats. $10^{\text {th }}$ edn, W.B. Saunders Elsevier, Philadelphia. pp. 211-215.

Saini, N. S., Kumar, A., Mohindroo, J., Singh, S. S., Anand, A., Mahajan, S. K., Raghunath, M., Chaudhary, M., Singh, N. and Toor, A. S. 2005. Clinical features and survival in reticular abscessation in buffaloes. Buffalo. J., 21: 167-173.

Sasikala, K., Vijayakumar, G., and Balasubramaniam, G.A., 2017. Endoscopic Evaluation of Reticulum in Cattle - A Preliminary Study. Indian Vet. J., 94 (05): $79-80$.

\section{How to cite this article:}

Sasikala, K., G. Vijayakumar, S. Sivaraman and Balasubramaniam, G.A. 2018. Clinico Diagnostic Studies on Reticular Abscess in Cattle - A Review of Four Cases. Int.J.Curr.Microbiol.App.Sci. 7(05): 524-527. doi: https://doi.org/10.20546/ijcmas.2018.705.066 